\title{
PENSATA
}

Submetida 29.09.2014. Aprovada 26.03.2015

Avaliada pelo processo de double blind review. Editora Científica: Fernanda Finotti Perobelli

DOI: http://dx.doi.org/10.1590/So034-759020150410

\section{GARANTIAS GOVERNAMENTAIS E COMPETITIVIDADE NO SETOR FINANCEIRO}

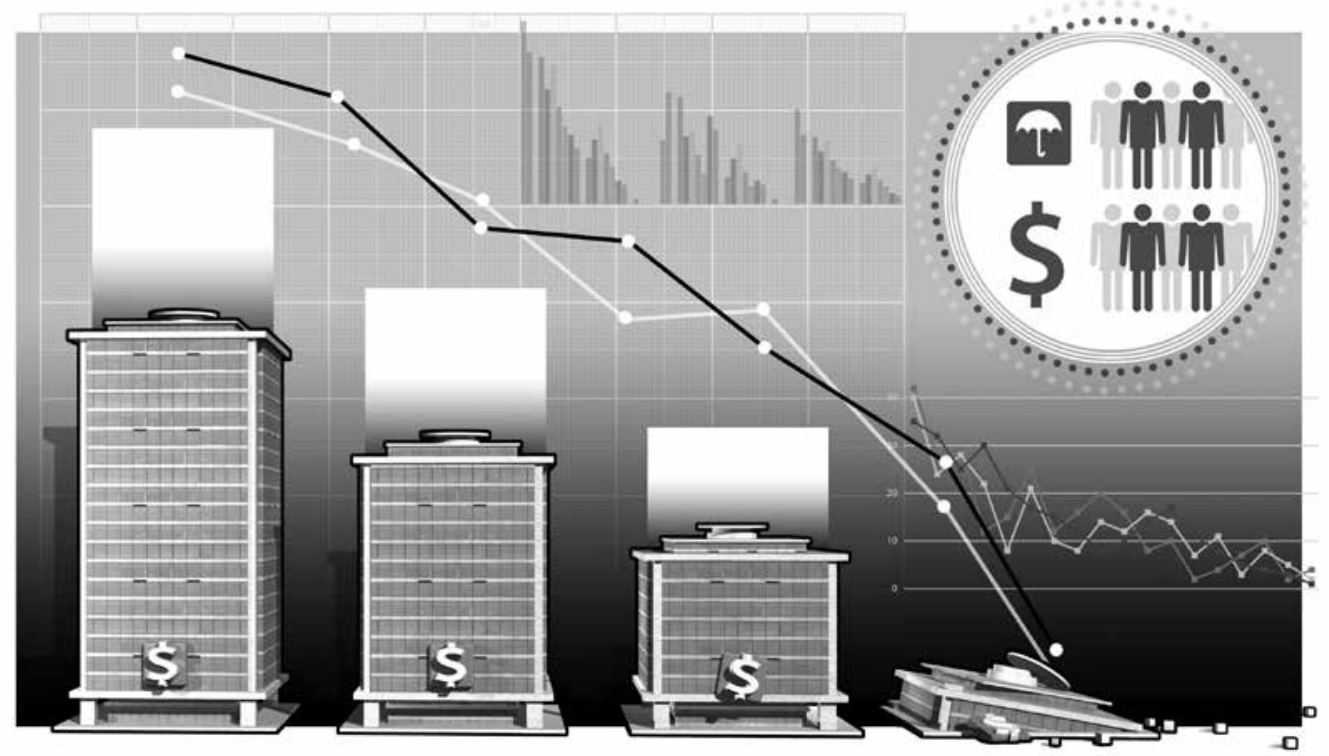

A maioria dos sistemas financeiros conta com algum tipo de garantia a passivos bancários. Esses mecanismos foram criados com o objetivo de diminuir a incidência de corridas bancárias e garantir a poupança de pequenos investidores. Garantias governamentais (ou quase governamentais) dadas a passivos bancários podem assumir várias formas. A mais comum é o que se costuma chamar de seguro-depósito: uma garantia aos depositantes, com valor limitado, em caso de falência do banco. Essa garantia pode ser oferecida por meio de uma seguradora oficial, como a Federal Deposits Insurance Corporation (FDIC), nos EUA, ou por uma entidade privada, que funcione num mecanismo de cosseguro entre os participantes, como o Fundo Garantidor de Crédito (FGC) no Brasil.

Durante a crise financeira global que se iniciou em 2007, houve uma série de intervenções governamentais que ampliavam as garantias aos passivos bancários, tanto em economias desenvolvidas quanto em emergentes. As medidas incluíam desde a ampliação dos valores de depósitos segurados até a nacionalização de instituições financeiras privadas. Por simplicidade, neste trabalho, eu me refiro a esse conceito ampliado de garantias simplesmente como seguro-depósito, a menos que seja expressamente necessário distinguir os diversos mecanismos de garantia.

RAFAEL SCHIOZER

rafael.schiozer@fgv.br

Professor da Fundação Getulio Vargas, Escola de Administração de Empresas de São Paulo - São Paulo - SP, Brasil
A literatura de Economia e Finanças tem tratado amplamente desse tema, e a pesquisa sobre os efeitos de garantias governamentais ganhou força após a crise. A contribuição principal do presente trabalho é sintetizar a literatura teórica, resumir e interpretar o conjunto de resultados empíricos a respeito do assunto e sugerir novas avenidas de pesquisa. 
Da maneira como estabelecido acima, esse objetivo pode soar muito ambicioso. Consequentemente, escolhi estreitar o escopo para: i) as teorias sobre garantias governamentais e ii) a interpretação conjunta dos resultados empíricos sobre o assunto, com atenção especial às pesquisas empíricas que tratam da recente crise financeira. Entendo que a compreensão conjunta desses estudos pode contribuir para a formulação de políticas que melhorem a estabilidade financeira e auxiliem o gerenciamento de eventuais futuras crises.

Obviamente, não seria possível cobrir todos os artigos sobre o tema neste trabaIho. Consequentemente, escolhi os estudos que considero mais representativos sobre 0 assunto. Essa escolha naturalmente carrega um viés dado por meus próprios interesses e experiência, bem como minha visão particular sobre os efeitos positivos e negativos das garantias governamentais sobre a estabilidade financeira.

Além desta seção introdutória, prossegue-se com as seguintes partes: a segunda seção descreve as vantagens e desvantagens dos esquemas de seguro-depósito; a terceira fornece um breve histórico dos esquemas de proteção vigentes no mundo; a quarta seção discute os efeitos do tratamento diferenciado dado a bancos sistemicamente importantes (too big to fail); a quinta apresenta avenidas para pesquisa futura, e a sexta seção conclui o ensaio.

\section{CORRIDAS BANCÁRIAS, VANTAGENS E DESVANTAGENS DO SEGURO-DEPÓSITO}

Corridas bancárias podem ter dois tipos de origem. Elas podem ocorrer espontaneamente, a partir de um pânico resultante da informação de que alguns depositantes estão sacando seus recursos (sunspot effect), como em Diamond e Dybvig (1983), ou podem ser causadas pela deterioração das condições econômicas, que afetam o sistema bancário como um todo ou alguns bancos em particular (Allen \& Gale, 1998; Jacklin \& Bhattacharya, 1988).

No modelo seminal de Diamond e Dybvig (1983), cada depositante bancário apresenta um fluxo de depósitos e saques baseado nas suas necessidades individuais de consumo e poupança ao longo do tempo. Ao haver, por qualquer que seja o motivo, um aumento exógeno nas necessidades de liquidez de alguns depositantes (isto é, uma demanda por dinheiro - não correlacionada com a qualidade da gestão do banco ou seu nível de risco - que ocasione alguns saques), cria-se um pânico: os demais depositantes, mesmo que não precisem do dinheiro, têm um incentivo para sacar rapidamente seus depósitos, sabendo que o banco é obrigado a negociar com desconto seus ativos de baixa liquidez (fire sales) para honrar os saques. Isso ocorre porque as perdas provocadas pelas transações com descontos ficam para os investidores remanescentes, já que o banco cobrirá os saques até ficar sem recursos (problema conhecido como first-come, first-served). Essa transferência de perdas incentiva todos os investidores a sacarem, independentemente da necessidade e da solvência anterior do banco.

No segundo tipo de motivação para corridas bancárias, apresentado por Jacklin e Bhattacharya (1988), os investidores diferenciam as instituições com bons e maus fundamentos, e a corrida bancária é restrita às instituições problemáticas.

Goldstein e Pauzner (2005) modificam os modelos de Diamond e Dybvig (1983) e Jacklin e Bhattacharya (1988), considerando os fundamentos econômicos como estocásticos, argumentando que os investidores não têm acesso total à informação, mas somente a um ruído. Nesse cenário, quando se exacerbam os problemas de assimetria de informação, caso típico de crises financeiras, os depositantes começam a sacar seus recursos, tornando a probabilidade de ocorrer corrida bancária endógena no modelo, dependente do nível de assimetria informacional sobre ativos e passivos do banco. A corrida bancária continua sendo alimentada pelo receio dos depositantes de que outros investidores tomem a decisão de sacar seus recursos. A literatura teórica e empírica sobre crises e corridas bancárias e suas consequências é extensa, e sua descrição fugiria ao escopo do presente texto. Uma ótima revisão sobre o assunto pode ser encontrada em Laeven (2011).

\section{Vantagens do seguro-depósito}

A visão dos pânicos de Diamond e Dybvig (1983) argumenta que corridas bancárias são profecias autorrealizáveis e que há múltiplos equilíbrios possíveis. Nesses modelos, que associam corridas bancárias a pânico, os depositantes sacam seus recursos se eles esperam que outros façam o mesmo. Num primeiro equilíbrio, se nenhum depositante acreditar que vai ocorrer pânico, apenas aqueles depositantes com reais necessidades de liquidez sacarão seus recursos. No segundo equilíbrio possível, se os agentes acreditam que haverá muitos saques, então isso se torna uma profecia autorrealizável, porque as pessoas sacarão mesmo que não tenham necessidade de liquidez. Como consequência, o banco tem que liquidar seus ativos de longo prazo a um custo e pode falir.

Nesse sentido, o seguro-depósito é uma ferramenta de seleção entre os equilíbrios possíveis. Se os depositantes que não precisam de liquidez tiverem a certeza de que receberão seus depósitos, eles não terão incentivo para sacar os recursos. 0 efeito benéfico não é apenas ex-post, isto é, sobre os agentes que já tenham depósitos em bancos. Ex-ante, o seguro depósito incentiva os agentes a depositarem seus recursos e sacarem apenas quando necessitarem de liquidez. Assim, o seguro-depósito tem um valor social, associado à ampliação da capacidade de intermediação financeira e ao aumento da estabilidade do sistema bancário (Allen \& Carletti, 2010). 


\section{Desvantagens do seguro- depósito}

Se as corridas bancárias decorrerem unicamente de pânico entre os depositantes, então a existência do seguro-depósito é sempre ótima. No entanto, Boot e Greenbaum (1993) apontam pelo menos dois pressupostos de Diamond e Dybvig (1983) que, se relaxados, implicariam custos sociais importantes para o provimento do seguro-depósito. O primeiro é a pressuposição de que o seguro não tem nenhum efeito ex-ante sobre o comportamento de bancos e depositantes. 0 segundo é que nem o banco, nem o segurador incorrem em custo para provê-lo, visto que o único equilíbrio possível é a não utilização do seguro.

Em Diamond e Dybvig (1983), o risco dos ativos bancários é exógeno e fixo. Assim, o seguro-depósito não tem influência sobre o incentivo para que os bancos se comportem de maneira mais ou menos prudente, nem sobre os incentivos para que os depositantes monitorem a escolha de risco feita pelo banco e decidam entre bancos mais ou menos seguros para depositar seus recursos.

Boot e Greenbaum (1993) mostram que, na presença de passivos segurados, há um problema de risco moral (moral hazard): um incentivo para que o banqueiro desloque o risco para o segurador, ao remunerar seus passivos a uma taxa inferior à taxa que seria "justa" para o nível de risco assumido nos ativos. Assim, se, por um lado, o seguro-depósito previne corridas causadas por pânico, o trade-off dessa vantagem é o aumento do risco no sistema financeiro, que pode resultar em custos para o provedor de seguros.

Allen, Carletti, e Leonello (2011) destacam que, se os prêmios de seguro forem corretamente precificados, o financiamento do banco deixa de ser subsidiado pelo segurador, e o incentivo para assumir riscos em excesso é eliminado. Na prática, a estimativa correta do risco dos passivos de uma instituição financeira é complexa e de- penderia da observação perfeita de seus ativos pelo segurador. Um exemplo dessa dificuldade em estimar prêmios corretos de seguro pode ser visto na crise financeira iniciada em 2007: o seguro oferecido por meio de credit default swaps por agentes privados carregava risco sistêmico não considerado nos prêmios de seguro.

Cooper e Ross (2002) mostram que uma segunda maneira de mitigar os problemas de risco moral é requerer capital suficiente dos bancos, de modo que o banqueiro seja o primeiro a assumir as perdas no valor dos ativos, incentivando o banco a se comportar prudentemente. Embora haja pouca dúvida de que o requerimento de capital mitigue o problema de risco moral, a exigência regulatória de capital poderia diminuir a oferta de crédito se houver custos associados a levantar capital (Elliot, 2010). No entanto, essa hipótese que sugere a existência de um trade-off entre a estabilidade do sistema e a oferta de crédito é contestada por autores como Admati e Hellwig (2013) e parece encontrar pouco respaldo empírico. Trabalhos como os de Francis e Osborne (2009), com bancos do Reino Unido; Berrospide e Edge (2010), nos EUA; e Yoshida e Schiozer (no prelo), no Brasil, encontram que o volume de crédito concedido pelos bancos é pouco sensível a variações do capital.

0 segundo pressuposto fundamental do modelo de Diamond e Dybvig (1983) é a credibilidade do esquema de seguro. Leonello (2013) mostra que a existência de garantias pode limitar a capacidade dos governos em se financiar no mercado de títulos e, por sua vez, sua habilidade de honrar o seguro. Mais importante, a qualidade dos ativos bancários está ligada à solvência do governo, uma vez que as flutuações macroeconômicas que a afetam tendem a afetar também os bancos (uma recessão afeta negativamente tanto os ativos bancários quanto a credibilidade do seguro-depósito). Assim, a extensão de garantias pode implicar uma dificuldade ainda maior de finan- ciamento do governo e, eventualmente, a perda de credibilidade de que as garantias serão honradas.

Há, portanto, um efeito de retroalimentação entre o risco soberano e o risco do sistema bancário. As recentes crises soberanas da zona do Euro são um exemplo desse efeito. Leonello (2013) mostra que a introdução de garantias gera um trade-off: por um lado, as garantias reduzem a probabilidade de uma corrida bancária, ao limitar a coordenação entre depositantes; por outro lado, implicam um aumento do custo da dívida do governo e da probabilidade de um default soberano. 0 estudo conclui que a existência de garantias parciais é uma solução ótima, dependendo da relação entre os custos de uma corrida bancária e os de um default da dívida soberana.

De fato, a maioria dos países adota, em tempos normais, garantias limitadas a um valor máximo (Schich, 2009). No entanto, durante crises bancárias, essas garantias são comumente ampliadas, incluindo até a injeção de capital e o salvamento das instituições com problemas, de maneira não prevista no esquema oficialmente vigente.

Ennis e Keister $(2009,2010)$ e Chari e Kehoe (2010) mostram que a ampliação de garantias em situações excepcionais gera um problema aos bancos centrais: ex-ante, o banco central não pode se comprometer a salvar bancos insolventes, pois isso ampliaria o risco moral. No entanto, ex-post, o banco central escolhe salvar bancos importantes, mesmo que insolventes, para evitar crises sistêmicas. Nesse sentido, é difícil que a política de não salvar bancos seja crível. Pode haver uma percepção geral de que, uma vez adotadas em uma crise, as garantias governamentais generalizadas estarão sempre disponíveis, caso necessário. Os agentes comportam-se esperando uma garantia implícita.

A expectativa de salvamento por parte dos investidores traz distorções importantes, que são ainda maiores se a expectativa 
de salvamento for diferenciada entre bancos. Alguns trabalhos recentes mostram evidência de que os agentes esperam o salvamento de alguns bancos (os chamados too big to fail), mas não de outros. Esses trabalhos serão discutidos nas considerações finais.

\section{OS ESQUEMAS DE SEGURO- DEPÓSITO NO MUNDO}

Os primeiros mecanismos bem documentados de seguro-depósito surgiram nos EUA na primeira metade do século XIX. O New York Safety Fund foi estabelecido em 1829, financiado por contribuições de instituições financeiras participantes. Nos primeiros anos, o sistema funcionou bem, mas entre 1837 e 1841, as perdas passaram a corroer o patrimônio do fundo, até que, em 1842 , ele se tornou insolvente por causa do grande número de falências bancárias. Calomiris (1990) mostra que as perdas sofridas pelo fundo foram derivadas de fraudes e práticas bancárias pouco apropriadas.

0 primeiro esquema de seguro-depósito ligado ao governo federal nos EUA foi introduzido em 1933, em resposta às corridas bancárias que aconteceram durante a grande depressão. Segundo Friedman e Schwartz (1963), a Lei Bancária de 1933 partiu do pressuposto de que a instabilidade financeira era derivada de um pânico da população, o que mostrava a necessidade de um instrumento que restabelecesse a confiança dos agentes no sistema bancário. A lei criou o FDIC, que provia seguro para os depósitos em bancos associados ao Federal Reserve. Diferentemente dos esquemas anteriores, o financiamento do seguro-depósito era bancado pelo Tesouro americano. 0 sistema restabeleceu a confiança dos agentes e foi fundamental para a recuperação econômica do país.

Grande parte dos países passou a adotar mecanismos formais de garantias a passivos bancários a partir da década de 1990 (Schich, 2009). No Brasil, foi criado, em 1995, o FGC, associação sem fins lucrativos que gerencia o mecanismo de seguro-depósito no País. A criação do $\mathrm{FGC}$ seguia as recomendações prudenciais do Basel Committee for Bank Supervision (BCBS) e ocorreu no âmbito da estabilização econômica e da reestruturação do sistema bancário de 1994-1995, que incluiu a recuperação de grandes bancos, em programas como o Programa de Estímulo à Reestruturação e ao Fortalecimento do Sis tema Financeiro Nacional (Proer), o Programa de Incentivo à Redução do Setor Público Estadual na Atividade Bancária (Proes) e o Programa de Fortalecimento das Instituições Financeiras Federais (Proef), e a falência de alguns bancos de menor porte. A participação no FGC é compulsória para as instituições do Sistema Financeiro Nacional, e o FGC é de propriedade dos membros participantes, caracterizando-se, portanto, como um mecanismo de cosseguro. Na data da criação, o limite segurado era de $\mathrm{R} \$ 20$ mil por depositante. Esse limite vem sendo gradualmente ampliado, tendo chegado a $\mathrm{R} \$ 250$ mil em 2014 (FGC, 2014). Uma excelente revisão sobre os programas de reestruturação de 1994-1995 no Brasil pode ser encontrado em Goldfajn, Hennings, e Mori (2003).

\section{EFEITOS DO TRATAMENTO DIFERENCIADO AOS BANCOS SISTEMICAMENTE IMPORTANTES}

Durante crises, os reguladores costumam ampliar explicitamente as garantias do sistema bancário, o que está associado a um aumento do risco moral ex-ante. Outras garantias, geralmente implícitas, privilegiam apenas um subconjunto de bancos, chamados sistemicamente importantes ou grandes demais para falir (too big to fail). Há diversas definições para o conceito de bancos grandes demais para falir. Por exemplo, para Kaufman (2014), uma empresa (ou banco) é definida como "grande demais para falir" quando requer: i) regulação especial para desencorajar a falência enquanto estiver viva e/ou ii) um regime de resolução de falência especial, em que o governo possa intervir de maneira que a firma não seja liquidada pelos processos usuais de falência que se aplicam às demais empresas. No caso de instituições financeiras, normalmente, a resolução de falência dá-se com a garantia (geralmente irrestrita) a seus passivos.

A coexistência, no mesmo sistema financeiro, de bancos que gozam dessa garantia implícita com bancos que não têm expectativa de serem salvos gera distorções competitivas importantes. Os efeitos ocorrem não somente nos bancos que potencialmente serão salvos mas também naqueles que não serão.

A literatura empírica sobre as políticas de salvamento diferenciadas foca três assuntos principais: i) seu efeito sobre o risco dos bancos; ii) o valor das ações e títulos desses bancos no mercado e iii) o comportamento dos depositantes e o maior acesso a liquidez por parte desses bancos durante crises financeiras.

A maior parte da literatura empírica sobre o efeito das garantias sobre o risco bancário (Boyd \& Runkle, 1993; Dam \& Koetter, 2012; Schnabel, 2009, entre outros) indica um aumento do risco bancário devido às garantias. Esses trabalhos, no entanto, desconsideram a existência de garantias diferenciadas (implícitas ou explícitas) dadas aos diferentes bancos do sistema. Hakenes e Schnabel (2010) desenvolvem um modelo que conclui que bancos colocados em desvantagem em termos de proteção governamental assumem maiores riscos (em comparação a uma situação em que a proteção é homogênea). Gropp, Hekenes, e Schnabel (2011) confirmam empiricamente essa hipótese. Esse resultado advém principalmente do fato de haver seleção adversa na escolha dos ativos. Bancos com proteção governamental têm custo de captação reduzido, por isso são capazes de oferecer emprés- 
timos a taxas mais baixas. Os melhores tomadores migram para os bancos protegidos, e os bancos sem proteção acabam ficando com os piores tomadores. Essa distorção diminui a eficiência do sistema bancário no longo prazo.

Em outra linha, O'Hara e Shaw (1990) investigam o efeito do anúncio pelo regulador americano de que alguns bancos seriam grandes demais para falir. 0 anúncio teve efeito positivo no preço das ações desses bancos e negativo nos demais. 0 efeito foi mais forte para os bancos menos solventes, evidenciando que a garantia significa um subsídio aos bancos protegidos. Brewer e Jagtiani (2011) estimam um prêmio total de US\$ 15 bilhões no preço das ações em oito operações de fusão que deram origem a bancos too big to fail nos EUA, e Penas e Unal (2004) mostram uma valorização dos passivos emitidos por bancos quando há anúncio de fusões que dão origem bancos sistemicamente importantes.

Oliveira, Schiozer, e Barros (2015) investigam o efeito de garantias implícitas sobre os depositantes brasileiros. Durante a crise financeira que se seguiu à quebra do Lehman Brothers em 2008, houve uma fuga massiva de depósitos de bancos pequenos e médios para aqueles considerados sistemicamente importantes, que não é explicada pelos fundamentos dos bancos, mas, sim, pela garantia implícita dada aos grandes bancos. Schiozer e Oliveira (2015) estudam a transmissão desse choque de depósitos ao crédito e mostram que, enquanto os bancos que perderam depósitos foram obrigados a cortar a oferta de empréstimos, os bancos que receberam depósitos não aumentaram a oferta de crédito. Assim, o choque de depósitos, que apenas redistribui os recursos entre os bancos, reduz a oferta global de crédito. Esse fenômeno pode ter duas explicações: i) empréstimos dependem de relacionamentos de longo prazo entre banco e cliente; assim, tomadores que se relacionam com bancos sem importância sistêmica não conseguem rapidamente tomar crédito em outros bancos; ii) os bancos sistemicamente importantes deliberadamente decidiram manter mais liquidez, como uma espécie de seguro para a crise.

\section{AVENIDAS FUTURAS DE PESQUISA}

A maioria dos resultados empíricos apresentados até aqui aponta na mesma direção em vários aspectos, a saber: i) as garantias governamentais incentivam os bancos a assumirem mais risco; ii) garantias diferenciadas entre bancos, mesmo que implícitas, geram distorções competitivas; iii) os choques negativos de depósitos transmitem-se para a oferta de crédito bancário.

No entanto, não se explica por que choques positivos de liquidez não aumentam a oferta de crédito. A teoria (por exemplo, Holmstron \& Tirole, 1997) indica que a transmissão pode depender de três fatores:

- outros fatores que restrinjam os empréstimos (por exemplo, o capital regulamentar): um choque positivo de liquidez pode ter efeito pequeno no relaxamento dessa restrição, e o efeito no crédito seria pequeno ou nulo;

- o nível de incerteza sobre a liquidez futura: se os gestores têm dificuldade em saber se o choque positivo de liquidez é permanente ou transitório, adotarão alguma precaução, mantendo liquidez adicional até que tenham indicações de que o choque é permanente;

- a existência de fricções que impeçam que relacionamentos bancários sejam estabelecidos rapidamente.

Assim, uma avenida importante de pesquisa que se desenha é a elucidação do mecanismo por trás dos resultados encontrados por Schiozer e Oliveira (2015). Testes em situações de crise e fora dela podem elucidar se a ausência de transmissão de choques positivos para a oferta de crédito, encontrada na crise brasileira, se deve a uma limitação por capital regulatório, à pre- caução dos gestores em se desfazer de liquidez ou à dificuldade em estabelecer relacionamentos bancários.

A identificação da causa precisa do mecanismo de transmissão é relevante, pois cada uma das possíveis explicações levaria a diferentes políticas públicas. Se o capital regulatório for um limitador, a adoção de um colchão de capital contracíclico (previsto no terceiro acordo de Basileia) seria uma solução viável. Se houver fricções que impeçam os tomadores de se relacionar com novos bancos rapidamente, seria desejável a construção de um cadastro positivo de crédito, para que os bancos possam avaliar mais facilmente o risco dos clientes. Finalmente, se a ausência de transmissão se der por conta de receio dos gestores em se desfazer de liquidez, medidas que garantam o provimento abundante e continuado de liquidez, como o estímulo ao mercado secundário de operações de crédito, são as mais indicadas.

A segunda avenida de pesquisa está relacionada às proposições de Leonello (2013) sobre o efeito de retroalimentação entre garantias governamentais dadas aos passivos bancários e o risco soberano. Uma questão em aberto é se a deterioração da situação fiscal de um país reduz a expectativa de salvamento de bancos sistemicamente importantes. Se sim, outra questão pertinente é se essa redução na probabilidade de salvamento traz impactos nos riscos assumidos pelos bancos.

Finalmente, uma terceira avenida que se desenha consiste numa extensão em nível internacional da pesquisa de Oliveira, Schiozer, e Barros (2015), em especial sobre a percepção de credores bancários e depositantes sobre garantias a bancos que têm importância sistêmica global. A designação, pelo Financial Stability Board, de um banco como Global Systemically Important Financial Institution (G-SIFI) pode ser uma informação importante aos agentes, que talvez reajam a essa designação. 


\section{CONSIDERAÇÕES FINAIS}

As deficiências dos sistemas vigentes no período anterior à recente crise financeira trouxeram o debate sobre reformas nos esquemas de garantias a depósitos à tona. Um esquema especificado ex-ante pretende proteger pequenos depositantes e limitar o poder de intervenção governamental.

No entanto, por conta da importância do sistema bancário para a economia, os governos tendem a intervir mais do que o pré-especificado. Medidas de emergência adotadas durante crises, como o salvamento de bancos, reduzem os impactos negativos imediatos, restabelecendo a confiança dos investidores no sistema bancário, mas têm efeitos nefastos no longo prazo: cria-se a expectativa de que o governo salvará instituições financeiras importantes sempre que necessário. Essa garantia implícita enfraquece a disciplina de mercado, incentiva os bancos a assumirem mais risco, e gera distorções competitivas entre os bancos considerados grandes demais para falir e aqueles sem garantia. A literatura empírica tem documentado que essas distorções são verificadas em vários mercados e em diferentes contextos.

Segundo Allen e Carletti (2010), seria desejável que o regulador pudesse comprometer-se a não ampliar o sistema de garantias anunciado. Isso requer que haja uma série de condições para que o sistema de garantias seja crível e não haja expectativa de sua ampliação. É necessário que haja a possibilidade real de falência de bancos importantes, com uma legislação que restrinja o poder das autoridades de salvar bancos. Mas, para que os efeitos sejam minimizados, é necessário que haja procedimentos para a rápida liquidação de bancos falidos.

Como mostram Leonello (2013) e Acharya, Pedersen, Philippon, e Richardson (2010), outro ponto fundamental para que se limite a ampliação de garantias aos bancos está relacionado à interação entre essas garantias e a situação fiscal do país. A ado- ção de uma cobertura irrestrita coloca em dúvida a credibilidade do seguro, e pode dar origem a uma corrida bancária e à dívida soberana simultaneamente. Em especial nas crises que tenham suas origens ligadas à deterioração dos fundamentos dos bancos (e não a pânicos), há grande possibilidade de que o segurador efetivamente enfrente prejuízos. A crise de dívida soberana que se seguiu à crise bancária de 20072009 em vários países, como Portugal, Irlanda, Itália, Grécia e Espanha, mostra que a ampliação de garantias e as políticas de salvamento podem ter efeitos deletérios sobre a solvência dos países, com consequências negativas prolongadas sobre a atividade econômica.

No caso específico do Brasil, há uma série de desafios a serem enfrentados no que se refere ao seguro-depósito. Primeiro, o País adotou um esquema privado, de cosseguro entre os bancos, protagonizado pelo FGC. Os esquemas de cosseguro podem induzir a uma quebra de confiança no sistema por receio de contágio durante crises financeiras. Como o mercado brasileiro é concentrado, isso é ainda mais grave: a falência de um grande banco traria perda substancial aos demais, uma vez que as perdas seriam repartidas entre poucos participantes relevantes. Segundo, o patrimônio do FGC é insuficiente para cobrir os valores segurados em caso de quebra de um dos cinco maiores bancos do País. Os resultados de Oliveira, Schiozer, e Barros (2015) indicam que os depositantes percebem uma garantia implícita dada aos grandes bancos pelo governo, independente da capacidade financeira e solvência do FGC, o que parece implicar que o Tesouro Nacional estaria necessariamente envolvido num processo de salvamento em caso de falência de um grande banco, seja aportando recursos no banco falido diretamente, seja capitalizando o FGC. Em outras palavras, as sucessivas ampliações do limite de depósitos segurados por depositante parecem indicar que há pouca preocupação com o baixo patrimônio do FGC, insuficiente para cobrir depósitos segurados de um grande banco em caso de falência. Esse fato pode gerar uma percepção de que o próprio FGC seria salvo pelo Tesouro em caso de necessidade. Como não há previsão legal para tal tipo de operação, a maneira pela qual essa intervenção seria feita pode ser desordenada e complicada dos pontos de vista financeiro e jurídico. Assim, parece evidente a necessidade da melhor compreensão do papel do seguro-depósito e do FGC no sistema financeiro brasileiro, e do aperfeiçoamento da legislação vigente. Como evidenciado acima, há diversas avenidas de pesquisa que podem contribuir para o aperfeiçoamento do desenho do mecanismo de proteção a depositantes e sua regulação no Brasil.

\section{NOTA DE AGRADECIMENTO}

0 autor agradece ao apoio financeiro da Fundação de Amparo à Pesquisa do Estado de São Paulo (FAPESP), e aos comentários de dois revisores anônimos que contribuíram para o aperfeiçoamento do texto.

\section{REFERÊNCIAS}

Acharya, V., Pedersen, L., Philippon, T., \& Richardson, M. (2010). Measuring systemic risk [Working Paper]. Federal Reserve Bank of Cleveland. Recuperado de http:// www.clevelandfed.org/research/workpaper/2010/wp1002.pdf

Admati, A. R., \& Hellwig, M. (2013). The bankers' new clothes: What's wrong with banking and what to do about it. Princeton: Princeton University Press.

Allen, F., \& Gale, D. (1998). Optimal financial crises. Journal of Finance, 53(4), 1245-1284. doi:10.1111/0022-1082.00052

Allen, F., \& Carletti, E. (2010). Financial regulation going forward (Discussion paper No. 2010-E-18). Institute for Monetary and Economic Studies, Bank of Japan. Recuperado de Institute for Monetary and Economic Studies: http://www.imes.boj.or.jp/research/papers/english/10-E-18.pdf. 
Allen, F., Carletti, E., \& Leonello, A. (2011). Deposit insurance and risk taking. Oxford Review of Economic Policy, 27(3), 464-478. doi:10.1093/oxrep/grro22

Berrospide, J. M., \& Edge, R. M. (2010). The effects of bank capital on lending: What do we know, and what does it mean? International Journal of Central Banking, 6(34), 1-50.

Boot, A., \& Greenbaum, S. I. (1993). Bank regulation, reputation and rents: Theory and policy implications. In C. Mayer \& X. Vives (Eds.). Capital markets and financial intermediation. Cambridge: Cambridge University Press.

Boyd, J. H., \& Runkle, D. E. (1993). Size and performance of banking firms: Testing the predictions of theory. Journal of Monetary Economics, 31(1), 47-67. doi:10.1016/03043932(93)90016-9

Brewer, E., \& Jagtiani, J. (2011). How much did banks pay to become too-big-to-fail and to become systemically important? Journal of Financial Services Research, 43(1), 1-35. doi:10.1007/s10693-011-0119-6

Calomiris, C. W. (1990). Is deposit insurance necessary? A historical perspective. Journal of Economic History, 50(2), 283-295.

Chari, V., \& Kehoe, P. (2010, February). Bailouts, time inconsistency and optimal regulation. Federal Reserve Bank of Minneapolis Staff Report.

Cooper, R., \& Ross, T. W. (2002). Bank runs: Deposit insurance and capital requirements. International Economic Review, 43(1), 5572.

Dam, L., \& Koetter, M. (2012). Bank bailouts and moral hazard: Empirical evidence from Germany. Review of Financial Studies. Publicação eletrônica antecipada. doi:10.1093/ rfs/hhso56

Diamond, D., \& Dybvig, P. (1983). Bank runs, deposit insurance, and liquidity. Journal of Political Economy, 91(3), 401-419.
Elliott, D. J. (2010). A further exploration of bank capital requirements: Effects of competition from other financial sectors and effects of size of bank or borrower and of loan type. Washington: Brookings Institution.

Ennis, H. M., \& Keister, T. (2009). Bank runs and institutions: The perils of intervention. American Economic Review, 99(4), 15881607. doi:10.1257/aer.99.4.1588

Ennis, H. M., \& Keister, T. (2010). Banking panics and policy responses. Journal of Monetary Economics, 57(4), 404-419. doi:10.1016/j.jmoneco.2010.04.005

Francis, W., \& Osborne, M. (2009). Bank regulation, capital and credit supply: Measuring the impact of prudential standards. FSA Occasional Paper, 36, London.

Friedman, M., \& Schwartz, A. J. (1963). A monetary history of the United States, 1867-1960. Princeton, NJ: Princeton University Press.

Fundo Garantidor de Créditos. (2014). Regulamento do Fundo Garantidor de Créditos. Recuperado de http://www.fgc.org.br/upload/regulamento_p.pdf

Goldfajn, I., Hennings, K., \& Mori, H. (2003). Brazil's financial system: Resilience to shocks, no currency substitution, but struggling to promote growth. Center for Research on Economic Development and Policy Reform, Stanford University.

Goldstein, I., \& Pauzner, L. (2005). Demand-deposit contracts and the probability of bank runs. Journal of Finance, 60(3), 1293-1327. doi:10.1111/j.1540-6261.2005.00762.x

Gropp, R., Hakenes, H., \& Schnabel, I. (2011). Competition, risk-shifting, and public bailout policies. Review of Financial Studies, 24(6), 2084-2120. doi:10.1093/rfs/hhq114

Hakenes, H., \& Schnabel, I. (2010). Banks without parachutes - competitive effects of government bail-out policies. Journal of Financial Stability, 6(3), 156-168. doi:10.1093/rfs/hhq114
Holmstrom, B., \& Tirole, J. (1997). Financial intermediation, loanable funds, and the real sector. The Quarterly Journal of Economics, 112(3), 663-691.

Jacklin, C. J., \& Bhattacharya, S. (1988). Distinguishing panics and information-based bank runs: Welfare and policy implications. The Journal of Political Economy, 96(3), 568-592.

Kaufman, G. (2014). Too big to fail in banking: What does it mean? Journal of Financial Stability, 13, 214-223. doi:10.1016/j. jfs.2014.02.004

Laeven, L. (2011). Banking crises: A review. Annual Review of Financial Economics, 3, 17-40. doi: 10.1146/annurev-financial-102710-144816

Leonello, A. (2013). Government guarantees and the two-way feedback between banking and sovereign debt crises. Recuperado de www.ssrn.com

O'Hara, M., \& Shaw, W. (1990). Deposit insurance and wealth effects: The value of being too big to fail. Journal of Finance, 45(5), 1587-1600.

Oliveira, R. F., Schiozer, R. F., \& Barros, L. A. B. C. (2015). Depositors' perception of "toobig-to-fail”. Review of Finance, 19(1), 191227. doi:10.1093/rof/rft057

Schich, S. (2009). Expanded guarantees for banks: benefits, costs and exit issues. $O E C D$ Journal: Financial Market Trends, 2009(3). Recuperado de http://www.oecd.org/

Schiozer, R. F., \& Oliveira, R. F. (2015). The asymmetric transmission of a bank liquidity shock. Recuperado de www.ssrn.com

Schnabel, I. (2009). The role of liquidity and implicit guarantees in the German twin crisis of 1931. Journal of International Money and Finance, 28(1), 1-25. doi:10.1093/rof/rfto57

Yoshida, V. T., \& Schiozer, R. F. (no prelo). Capital bancário e crédito no Brasil. RAC-Revista de Administração Contemporânea. 